\title{
A Review of Electrically-Assisted Manufacturing
}

\author{
Huu-Duc Nguyen-Tran', Hyun-Seok Oh'1, Sung-Tae Hong', Heung Nam Han², Jian Cao, \\ Sung-Hoon Ahn', and Doo-Man Chun ${ }^{1, \#}$ \\ 1 School of Mechanical Engineering, University of Ulsan, 93, Daehak-ro, Nam-gu, Ulsan, 44610, South Korea
2 Department of Materials Science and Engineering, Seoul National University, 1, Gwanak-ro, Gwanak-gu, Seoul, 08826, South Korea \\ 3 Department of Mechanical Engineering, Northwestern University, Evanston, IL 60208, USA \\ 4 Department of Mechanical Engineering, Seoul National University, 1, Gwanak-ro, Gwanak-gu, Seoul, 08826, South Korea \\ \# Corresponding Author / E-mail: dmchun@ulsan.ac.kr, TEL: +82-52-259-2706, FAX: +82-52-259-1680
}

KEYWORDS: Electroplasticity, Mechanical properties, Electrically-Assisted manufacturing

\begin{abstract}
The mechanical properties of metals change temporarily or permanently under application of electric currents under deformation. This phenomenon is often referred to as electroplasticity. The electroplasticity of metals and their alloys has been investigated under various loading conditions including tensile, compressive, bending, and hardness tests. Electrically-assisted manufacturing (EAM) utilizes this electroplasticity in manufacturing processes. Due to its technical advantages such as enhanced formability and reduced springback, EAM is energy efficient with reduced process time. Recent developments in EAM include various bulk deformation and sheet metal forming processes. This paper summarizes previously reported electroplastic behaviors of various metals or metal alloys and recent EAM processes. In addition, contemporary EAM patents are briefly reviewed.
\end{abstract}

Manuscript received: May 5, 2015 / Accepted: June 15, 2015

\section{Introduction}

Electrically-assisted manufacturing (EAM) is a new concept for manufacturing processes that utilize the electroplasticity of metals and their alloys. EAM is one of hybrid manufacturing processes aiming to improve productivity, efficiency, and quality. ${ }^{1-10}$ Various EAM studies have shown that the material properties of a metal can be modified simply by applying electricity to the metal during deformation. The classical works and studies by Troitskii, ${ }^{11}$ Okazaki, ${ }^{12}$ and Conrad ${ }^{13}$ provide good background information regarding the effect of electricity on the material properties of metals.

As recently reported by Ross et al. ${ }^{14}$ and Perkins et al., ${ }^{15}$ the presence of a continuous electric current during plastic deformation of a metal may significantly reduce the flow stress of the metal. Under compression, the formability of a metal is significantly enhanced with application of a continuous electric current. ${ }^{15}$ Studies have shown that the disadvantage of the reduced maximum elongation of metals under tension with a continuous electric current ${ }^{14}$ can be overcome by applying an electric current periodically (a pulsed electric current) instead of continuously. ${ }^{16-19}$

By properly utilizing the electroplastic behaviors of metals, EAM is expected to reduce the process time and manufacturing cost in various conventional manufacturing processes such as sheet metal forming or die forging. Since EAM is expected to be carried out at relatively lower temperatures compared to hot working, the common problems of hot working such as thermal stress, warp, and low controllability of tolerance can be minimized. Therefore, EAM is a cost-effective and energy-saving manufacturing process that also enhances the quality of products.

This review summarizes the previously reported electroplastic behaviors of various metals or their alloys in EAMs processes. Also, contemporary EAM patents are briefly reviewed.

\section{History of Electroplasticity}

In the 1960 s, Troitskii ${ }^{11}$ reported a phenomenon in which applying an electric current during deformation reduced the flow stress and increased the elongation of metals. In 1970s, Troitskii et al. ${ }^{20}$ also argued that the phenomenon could be induced by the effect of drifting electrons (electron wind) on dislocations and showed that flow stress could be reduced by using high-pulsed currents. After the work of Troitskii, the influences of continuous or pulsed electric current on mechanical properties such as flow stress, stress relaxation, creep, dislocation generation, mobility, brittle fracture, fatigue, and formability of various metals $s^{13,21-23}$ have been investigated. The 
magnitude of drifting electron-dislocation interaction under a pulsed electric current was determined in theory, ${ }^{20}$ while Okazaki et al. ${ }^{24}$ focused on the effects of crystal structure, impurities, skin effect, pinch effect, and resistance heating on the reduction of stress. Conrad et $\mathrm{al}^{25}$ studied the effect of a pulsed electric current on the mechanical behavior of metals.

The athermal effects of an electric current on the mechanical properties of metals under deformation are often referred to as electroplasticity. It has been reported that the electroplasticity of a metal affects the recrystallization, ${ }^{26-28}$ surface hardness, ${ }^{29}$ ductility and strength, ${ }^{30,31}$ elongation, ${ }^{19,32}$ and residual stress. ${ }^{33}$ Obviously, the process parameters of the electric current such as the use of a pulsed current and the current density based on the cross-sectional area perpendicular to the direction of the electric current are crucial factors $^{19,34-36}$ in the optimization of forming processes utilizing electroplasticity. ${ }^{37}$

It is natural that electric currents applied to a metal increase the temperature of the metal due to Joule heating, regardless of the magnitude of the temperature increase. The thermal (Joule heating) and athermal (electroplasticity) effects of a continuous electric current were studied by comparing the results of electrically-assisted forming by applying electric currents to metals during deformation with the results of conventional oven heating ${ }^{15}$ or hot working ${ }^{38}$ at temperatures equal to or higher than the temperature applied during the electricallyassisted forming. According to Perkins et al., ${ }^{15}$ even at lower temperatures, the stress reduction during the electrically-assisted compression of aluminum, copper, iron, and titanium-based alloys was clearly higher than that of conventional compression at elevated temperatures. Also, according to Dzialo et al., ${ }^{38}$ the temperature increase obtained during electrically assisted compression of copper alloys was lower than that during a hot working process at the same reduction of stress. Ross et al. ${ }^{39}$ suggested isolatable effects due to electricity such as Joule heating, kinetic energy (pushing dislocations), and retained stress-strain energy, while reporting that a higher resistivity of material induced a greater electroplastic effect. Salandro et al. ${ }^{40,41}$ assumed that the electric current during deformation produced only heating and deformation energy. He suggested a quantified electroplastic effect coefficient to separate the effects of the electric current into thermal and athermal effects. Moreover, it has been suggested that the threshold values of current density exist to induce an appreciable electroplastic effect on materials. ${ }^{42,43}$ Perkins et al. ${ }^{15}$ reported that the threshold was not obtained for the copper-based alloy evaluated in their study.

Regarding the mechanism of electroplasticity, hypotheses relating electrons and dislocations have been widely accepted. ${ }^{20,21,44,45}$ Kravchenko $^{44}$ suggested a theoretical explanation based on the interactions between electrons and dislocation movements (so called electron wind). He concluded that, if the velocity of drifting electrons exceeds the dislocation velocity, the force of the electrons on the dislocation becomes sufficient to accelerate the dislocation. Fiks ${ }^{46}$ suggested an electron wind model to calculate the diffusion of dislocation flow due to electric currents. He claimed that the effective dislocation charge, which is dragged by electrons, can be considerably large and becomes more apparent at a lower temperature since the mean free paths of electrons become longer. The drag force of

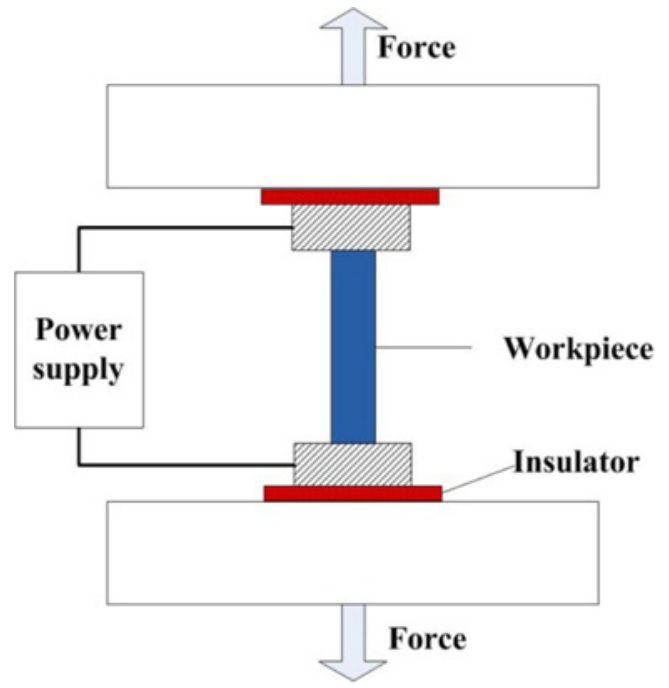

Fig. 1 A schematic of the experimental setup for electrically-assisted tensile testing (modified and redrawn from Ref. 14)

electron-dislocation interactions was assumed to be proportional to the difference between the velocity of the drifting electrons and the dislocation velocity. ${ }^{21}$

Li et al. ${ }^{47}$ studied the electroplastic effect on the microscopic scale based on the classical free-electron theory. Their results are consistent with Conrad's theory for the influence of a high pulsed current density on the flow stress of metals. ${ }^{42,43} \mathrm{Li}$ et al. ${ }^{48}$ also argued that the motion of electrons should be described by quantum laws, and the Schrödinger equation of ions and electrons needs to be solved in order to understand the electron state in metals.

On the other hand, the thermal effect of electric current has also been considered. Goldman et al. ${ }^{49}$ claimed that the interactions between electrons and dislocations are negligible at temperatures above $20 \mathrm{~K}$. Moreover, at $4.2 \mathrm{~K}$, there is no electroplastic effect on lead in the superconducting state, which cannot generate Joule heating due to a zero resistivity. Cao and co-workers ${ }^{50}$ reported that the stress reduction became negligible when the specimen was cooled by forced air during tensile testing with continuous electric currents and suggested that the role of Joule heating on the metal's plastic behavior should be reevaluated. In addition, Magargee et al. ${ }^{51}$ suggested the notion of current density sensitivity, which is a new parameter to determine the temperature increase with respect to current density.

\section{Material Properties in Electroplasticity}

The effects of electric current on the material properties of metals have primarily been evaluated based on tensile, compressive, bending, and hardness tests, as tabulated in Table 1 . The results generally show decreases in flow stress, energy for plastic deformation, and springback.

\subsection{Tensile Test}

A general schematic of the electrically-assisted tensile test is shown in Fig. 1. For tensile loading, enhanced formability and reduced flow stress are usually achieved by applying a pulsed electric current during deformation. ${ }^{52}$

For example, the poor formability of ultra-high strength steel sheets, 


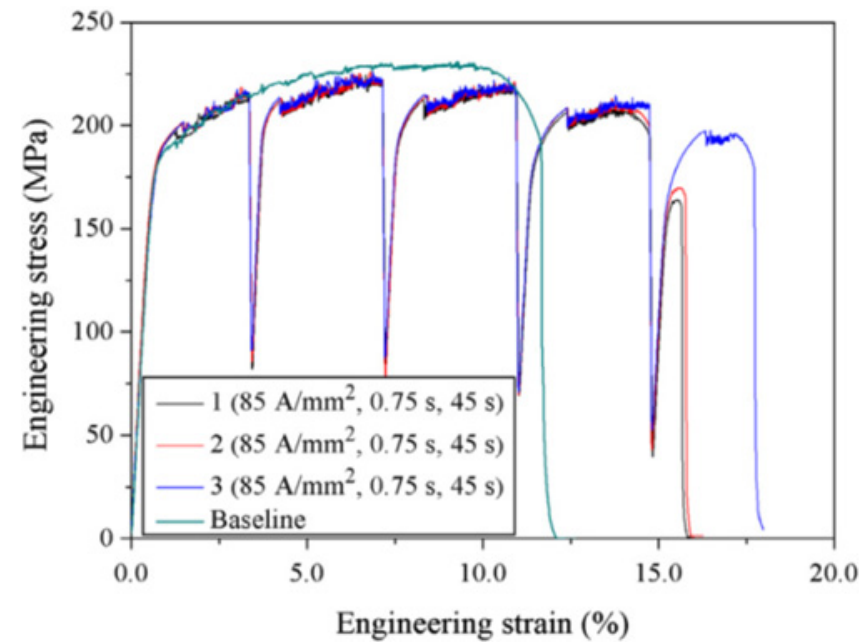

Fig. 2 Experiment results of 5052-H32 aluminum alloys under a pulsed electric current ${ }^{18}$

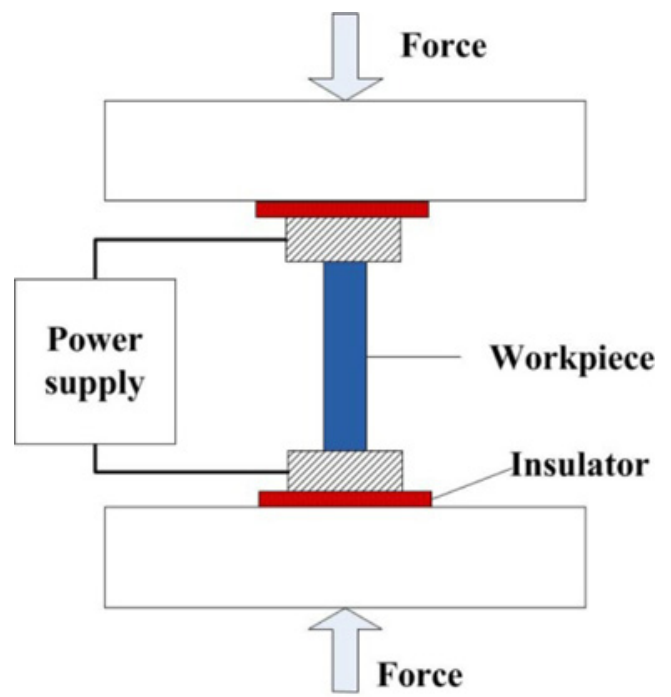

Fig. 3 A schematic of the experimental setup for the EA compression test (modified and redrawn from Ref. 63)

dual-phase steel sheets, and a magnesium AZ31B alloy was dramatically improved under pulsed electric currents in tensile testing. ${ }^{53-56}$ The plastic deformation of 70/30 brass was enhanced for both fine and coarse grain specimens when a continuous electric current was applied in uniaxial tension testing. ${ }^{57}$

The tensile properties under a pulsed electric current were also investigated for 5052 and 5083 aluminum alloys, ${ }^{19} 304$ stainless steel, ${ }^{58}$ and a Ti-6Al-4V alloy ${ }^{37,59}$ at high deformation rates. It was also confirmed that titanium alloys ${ }^{60,61}\left(\mathrm{VT} 1-0, \mathrm{VT} 6, \mathrm{Ti}_{49.3} \mathrm{Ni}_{50.7}\right)$, a ZA22 alloy, ${ }^{62}$ and a $5052-\mathrm{H} 32$ aluminum alloy ${ }^{18}$ showed electroplastic behavior during tensile deformation with pulsed electric currents (Fig. 2).

On the other hand, Mai et al. ${ }^{58}$ investigated the Joule heating effect on the strain of stainless steel. The plastic deformation increased when the resistivity increased due to Joule heating. However, at the same temperature, stress reduction was observed when the current density was increased from $5 \mathrm{~A} / \mathrm{mm}^{2}$ to $10 \mathrm{~A} / \mathrm{mm}^{2}$. For similar temperature profiles, Fan et al. ${ }^{57}$ compared the results of oven-heated tensile and electricallyassisted tensile tests. The ultimate tensile strength obtained in the

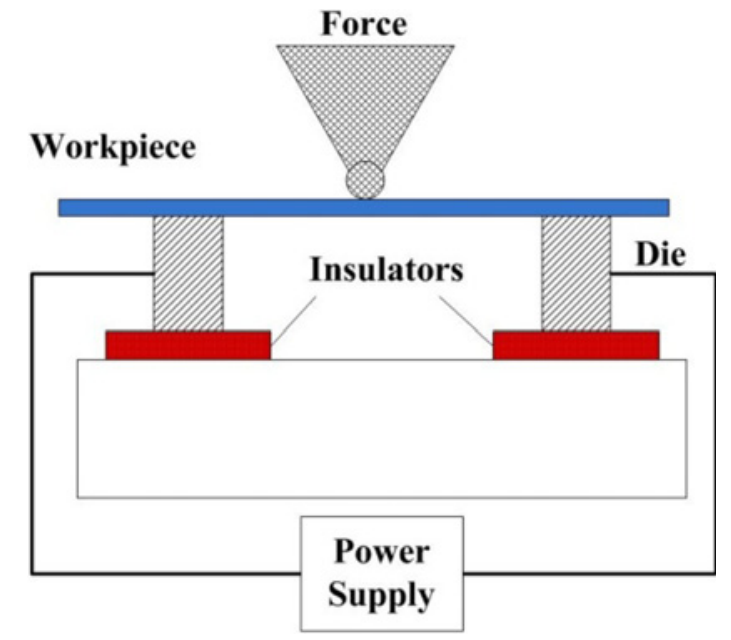

Fig. 4 A schematic of the experimental setup for the EA bending test (modified and redrawn from Ref. 40)

electrically-assisted tensile test was around $17 \%$ lower than that of the oven-heated tensile test. Moreover, Fan et al. ${ }^{57}$ also argued that local heating at grain boundaries can be attributed to plastic deformation due to easy movement of grain boundaries by heating.

\subsection{Compression Test}

The schematic of the electrically-assisted compression test is shown in Fig. 3. Perkins et al. ${ }^{15}$ reported the results for various materials investigated in electrically-assisted compression tests such as 304 stainless steel, 360 brass, and $6061 \mathrm{~T} 6511$ aluminum alloys. The contribution of electroplasticity of these materials decreased the total required energy versus current density. Dzialo et al. ${ }^{38}$ determined that the temperature also affected the stress reduction. However, the heating itself was not the only reason for the observed effects. Moreover, the threshold current density significantly affected stress reduction in the compression of a $\mathrm{Cu} 260$ alloy.

In addition, Siopis et al. ${ }^{64}$ reported that larger grain sizes of copper in the compression test were less affected by electroplasticity than were fine grain sizes due to the small surface area of the grain boundaries. Higher continuous electric currents were necessary to aid the motion of dislocations at the boundaries. Hence, with increasing grain size, the threshold current density increased and the stress reduction decreased. However, the electroplasticity also affected the grain size due to accelerated recrystallization. ${ }^{27}$

\subsection{Bending Test}

In the bending process, springback results in less accuracy in manufacturing. Springback can be decreased through the use of an annealing process. $^{65,66}$ However, electroplasticity can easily reduce or eliminate springback. Moreover, the quality of the surface can be largely improved. A schematic of the electrically-assisted bending test is shown in Fig. 4.

Salandro et al. ${ }^{40}$ reported that stress reduction, which was increased up to $77 \%$, depended on the pulsed electric current. The required energy was also reduced. An analytical model in which it is assumed that electric current produces only electroplasticity and Joule heating effects can be used to predict the bending forces. In addition, the springback reduction depends on current parameters such as a longer 


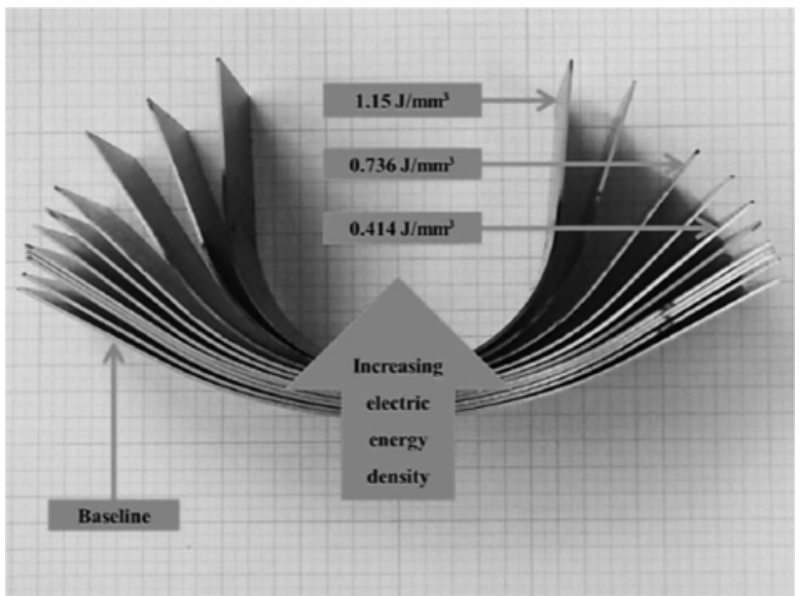

Fig. 5 Springback reduction of advanced high-strength steels with various current densities ${ }^{67}$

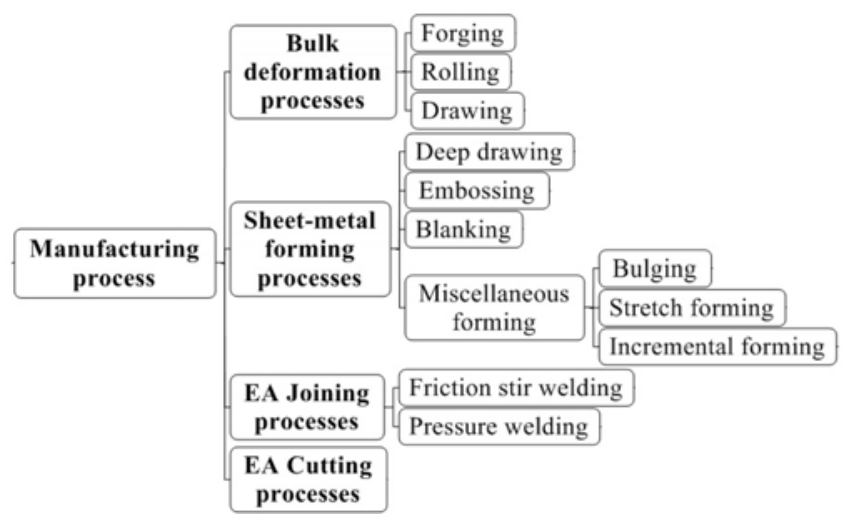

Fig. 6 A list of EAM processes

pulse duration and higher current density. ${ }^{68}$ Fig. 5 shows springback with respect to current density in the electrically-assisted bending test. ${ }^{67}$

\subsection{Hardness Test}

Parkansky et al. ${ }^{69}$ reported the dependence of electroplasticity on a magnetic structure $(\mathrm{Cu}$ and $\mathrm{Ni})$ at low current density. The current density $\left(100 \mathrm{~A} / \mathrm{cm}^{2}\right)$ significantly affected the ferromagnetic nickel indentation but only weakly influenced copper. They argued that this is due to the interaction between the current-induced magnetic field and magnetic domain wall. Moreover, $\mathrm{Ge}, \mathrm{Si}$, and $\mathrm{CdS}$ can be easily indented by applying a continuous electric current. ${ }^{29}$ In addition, in the bulk materials, the hardness of the specimen has only been mentioned before or after the electric current treatment. Therefore, electroplasticity has not been completely investigated in hardness testing.

\section{Electrically-Assisted Manufacturing Processes}

As electroplasticity has been widely studied, EAM processes have been increasingly suggested. The suggested EAM processes are mainly associated with bulk deformation and sheet-metal forming, as shown in Fig. 6. Furthermore, other processes such as joining processes and material-removal processes are considered to be potential applications in manufacturing processes.

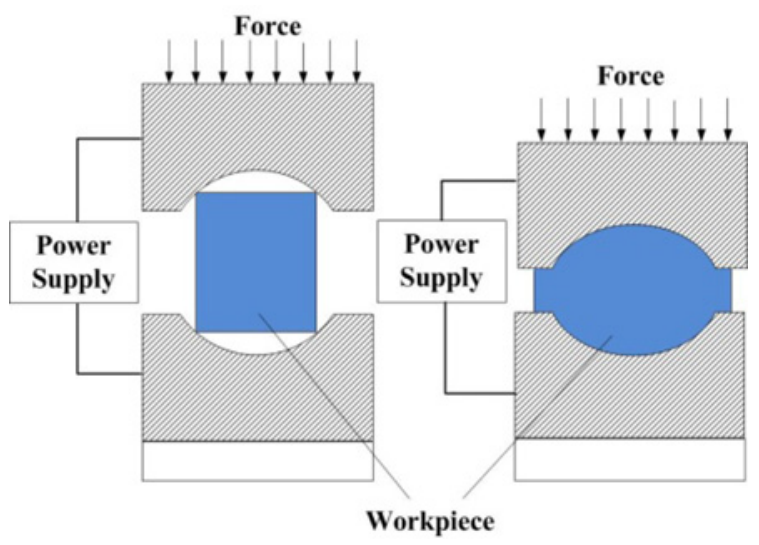

Fig. 7 A schematic of the EA forging process (modified and redrawn from Ref. 70)

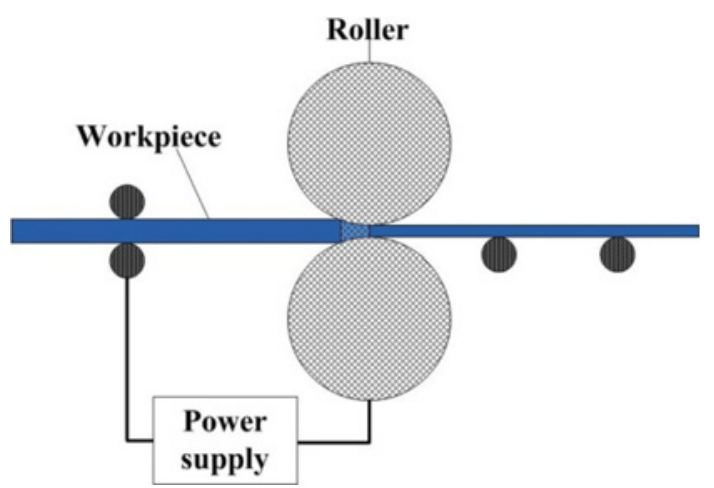

Fig. 8 A schematic of the EA rolling process (modified and redrawn from Ref. 75)

\subsection{Bulk Deformation Processes}

\subsubsection{EA Forging Process}

Ross et al. ${ }^{39}$ reported that the forgeability of Ti6A14V was clearly enhanced by a continuous electric current. Bunget et al. ${ }^{71}$ suggested that electroplasticity and Joule heating can be separated in energy modeling, which was confirmed in Perkins' studies on Al6061 specimens, in order to analyze and predict electroplastic behavior in the EA forging process. The schematic of the EA forging process is shown in Fig. 7.

Jones et al. ${ }^{70}$ also reported that the forgeability was significantly increased as the continuous electric current increased. The ability to form a final geometry, which is not achievable at room temperature, was achievable in the EA forging process. In addition, the overall required forces decreased at higher current densities. However, lower current densities provided similar forgeability enhancement at a particularly slower platen speed.

\subsubsection{EA Rolling Process}

Fig. 8 shows a schematic of the EA rolling process. With regard to the EA rolling process, $\mathrm{Xu}$ et al. ${ }^{72}$ report that the rolling force of a magnesium AZ31 alloy was largely reduced and its deformation was significantly improved while a satisfactory surface quality was obtained at room temperature. With similar results, $\mathrm{Lu}$ et al. ${ }^{73}$ reported that the rolling force and deformation of $\mathrm{Bi} 2223 / \mathrm{Ag}$ were reduced and improved, respectively. Furthermore, the tensile fracture of a magnesium AZ91 alloy was brittle fracture in warm rolling, while it 


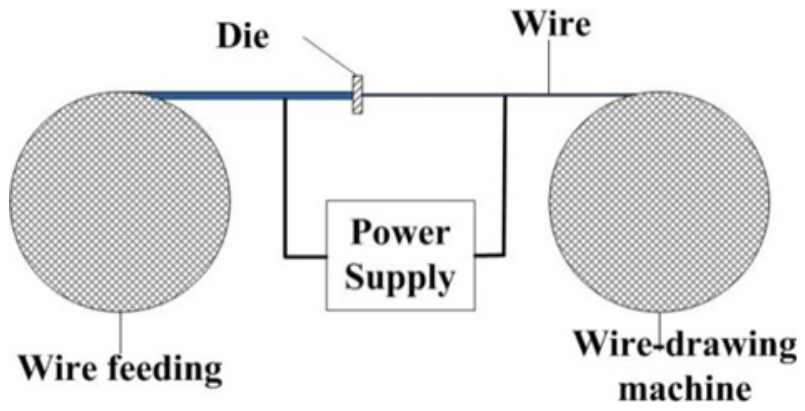

Fig. 9 A schematic of the EA drawing process (modified and redrawn from Ref. 77)

was dimple fracture in EA rolling at a pass reduction of $35 \%$. In addition, $\mathrm{NiTiNb}^{74}$ and $\mathrm{TiNi}^{75}$ were successfully rolled by a EA rolling process at a relatively low temperature or without intermediate annealing compared to traditional hot rolling.

In EA micro rolling, the texturing capability and channel depth of Ti-6Al-4V and AA3003-H14 were apparently enhanced. The forming pressure of EA micro rolling was lower than that of conventional micro rolling. ${ }^{76}$

\subsubsection{EA Drawing Process}

Tang et al. ${ }^{77}$ suggested the common EA drawing process shown in Fig. 9. The drawing forces of austenitic stainless steel wires, ${ }^{77-79}$ copper wire, ${ }^{80}$ and cast-ion wire ${ }^{81}$ decreased in the EA drawing process, while their surface qualities improved.

Tang et al. $^{79}$ claimed that the temperature increase did not significantly contribute to the changes in mechanical properties, resistivity, and surface quality of austenitic stainless steel in the EA drawing process. In particular, Stashenko et al. ${ }^{82}$ stated that the EA drawing process can reduce the production cycle and product cost due to the decreased drawing force and increased drawing velocity.

\subsection{Sheet-Metal Forming Process}

\subsubsection{EA Deep Drawing Process}

Wang $^{83}$ suggested a schematic for the EA deep drawing process using a pulsed electric current (Fig. 10). The lower resistance to deformation, better plasticity, improved ductility, dynamic recrystallized grains at low temperature, and low energy consumption are the advantages of the EA deep drawing process. Magnesium AZ31 alloy cups were successfully drawn by applying a pulsed electric current, and their plasticity was enhanced. The dynamic recrystallized grains of this process occurred at a lower temperature (above $200^{\circ} \mathrm{C}$ ) than conventional hot drawing $\left(350^{\circ} \mathrm{C}\right)$ due to thermal and athermal effects.

\subsubsection{EA Embossing Process}

Mai et al. $^{84}$ proposed an EA embossing process to improve the formability of material by applying a continuous electric current. Fig. 11 shows the schematic of the EA embossing process. This process was used to successfully fabricate micro channels on a SS316 L plate at $110^{\circ} \mathrm{C}$ in the present study. Compared to the traditional process, the die pressure was reduced, and the channel shape and the channel depth were enhanced. Moreover, in numerical simulation results, the residual stress was decreased in the high-residual stress region. The high-residual stress region was more concentrated at the corner of the channel.

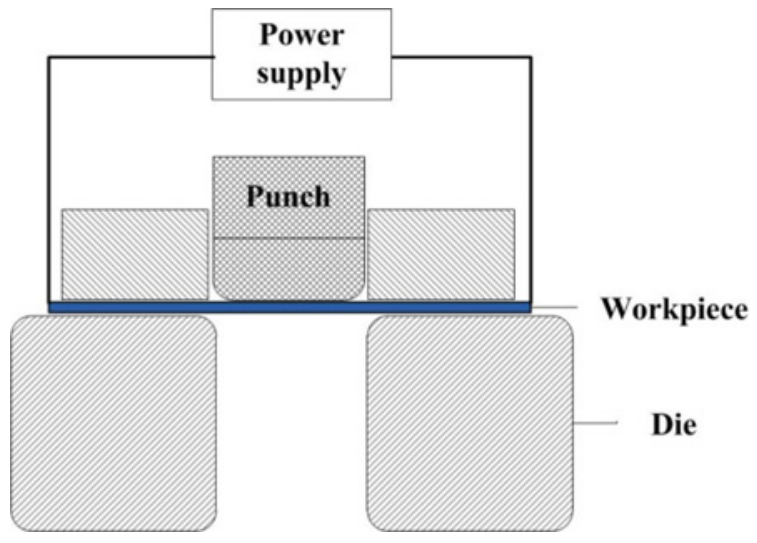

Fig. 10 A schematic of the EA deep drawing process (modified and redrawn from Ref. 83)

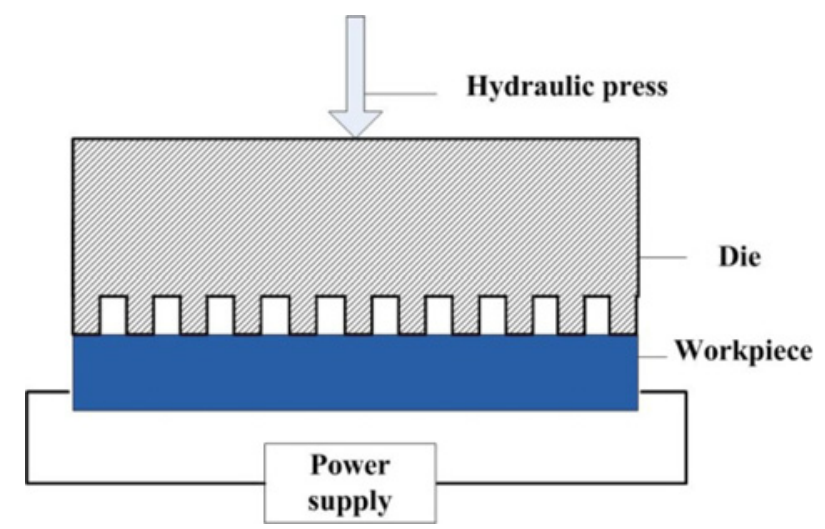

Fig. 11 A schematic of the EA embossing process (modified and redrawn from Ref. 84)

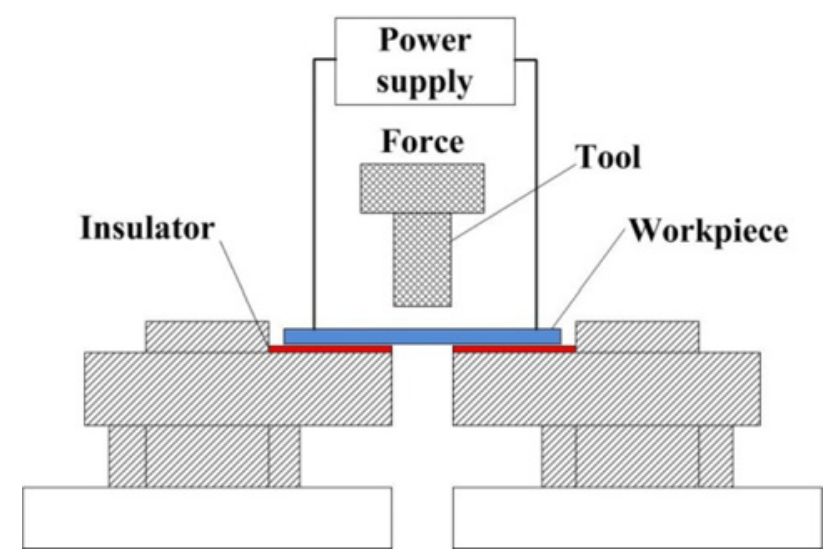

Fig. 12 A schematic of the EA blanking and RH blanking processes (modified and redrawn from Ref. 85)

\subsubsection{EA Blanking Process}

Kim et al. ${ }^{85}$ suggested EA blanking and local resistance heating blanking (RH blanking), which are described in Fig. 12. In EA blanking, a single pulsed electric current is connected to a workpiece while it is blanked. In RH blanking, only Joule heating is utilized to heat a workpiece before banking. Compared to RH blanking (nearly $175^{\circ} \mathrm{C}$ ) and cold blanking, the EA blanking load of ultra-high strength steel $\left(90 \mathrm{~A} / \mathrm{mm}^{2}-174^{\circ} \mathrm{C}\right)$ was decreased by approximately $20 \%$ and $85 \%$, respectively, due to electroplasticity. 


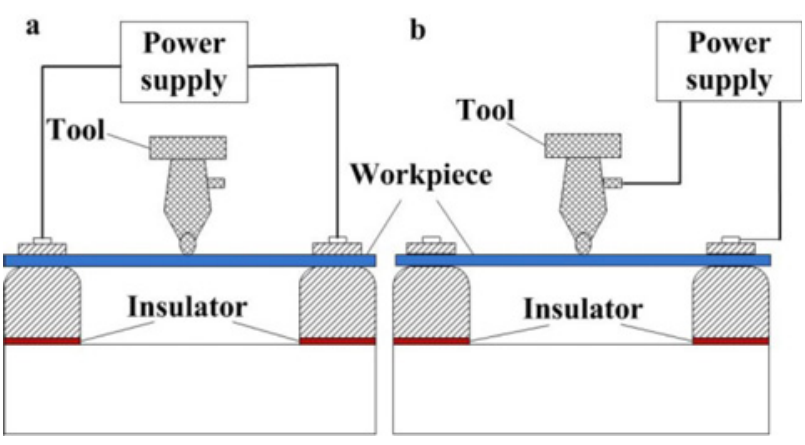

Fig. 13 A schematic of EA stretch forming processes; (a) Across the workpiece (b) Through the tool to the workpiece (modified and redrawn from Ref. 86)

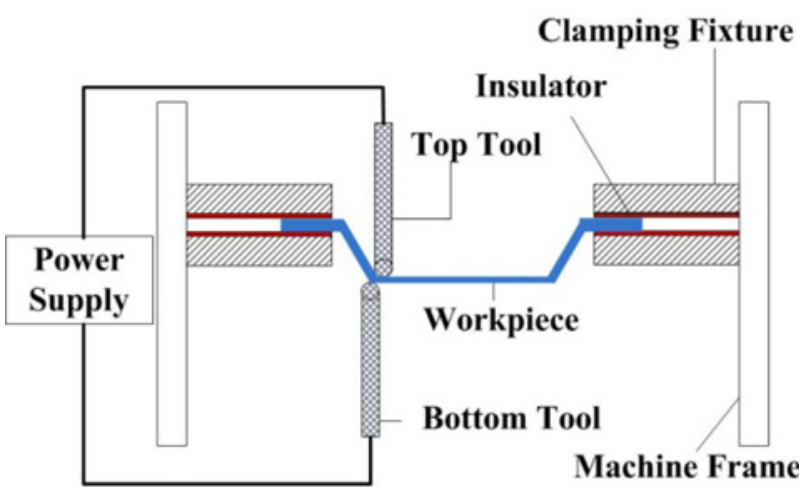

Fig. 14 A schematic of the EA incremental forming process (modified and redrawn from Ref. 88)

\subsubsection{Miscellaneous Forming Processes \\ 4.2.4.1 EA Stretch Forming Process}

Jones et al. ${ }^{86}$ provided a schematic of the EA stretch forming process, as shown in Fig. 13. Compared to the traditional process, the formability and forming force of a 6061 aluminum alloy were reduced in the pulsed electric current-assisted stretch forming process. However, the low current density $\left(10 \mathrm{~A} / \mathrm{mm}^{2}\right)$ did not appreciably reduce the forming force. Furthermore, the direction of the pulsed electric current and different application schemes did not significantly affect the formability or forming force.

\subsubsection{EA Incremental Forming Process}

Cao et al. ${ }^{87}$ suggested EA double-side incremental forming equipment for enhanced formability and geometrical flexibility. This equipment possessed high process controllability, low energy consumption, good typical part accuracy, and high part complexity. Asghar et al ${ }^{88}$ also successfully formed a titanium alloy using an EA double-side incremental forming process (Fig. 14). The pulsed electric current applied to the part of tools can greatly improve the forming limits of incremental forming parts and probably allow formation of exotic materials. Ti6Al4V, which can only be formed at temperatures of $900-930^{\circ} \mathrm{C}$, was successfully formed by applying a pulsed electric current at $47^{\circ} \mathrm{C}$ to a tool-sheet interface. Its force and the distortion of shape were reduced compared to those in the traditional process. In addition, electrically-assisted tools ensure that the zone of current conduction is as small as possible in order to enhance the formability due to electroplasticity.

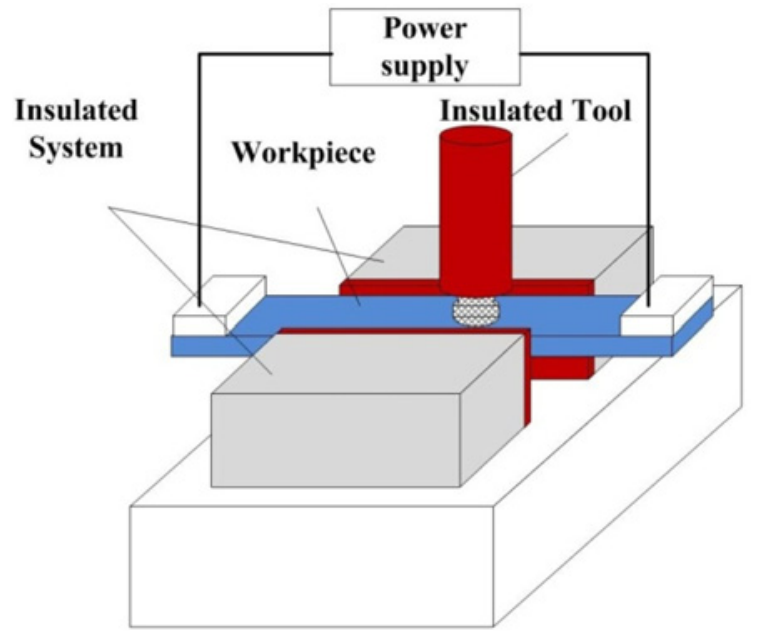

Fig. 15 A schematic of the experiment setup of the EAFSW process (modified and redrawn from Ref. 91)

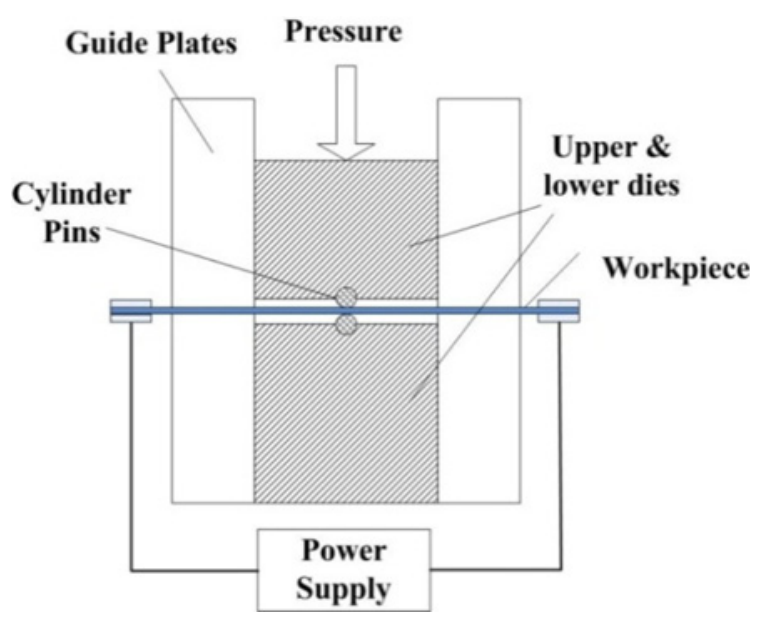

Fig. 16 A schematic of the EA pressure welding process (modified and redrawn from Ref. 92)

\subsection{EA Joining Process}

\subsubsection{EA Friction Stir Welding Process}

Electrically-assisted friction stir welding (EAFSW) was suggested as a new method for easy maintenance and flexible applications. The Z-axis force of EAFSW is decreased more significantly than that of the conventional process, ${ }^{89}$ and the weld speed and power consumption are improved. ${ }^{90}$ Recently, Potluri et al. ${ }^{91}$ reported that this process also eliminated the limited penetration depth and reduced tool wear in the plunge and weld (Fig. 15). A decreased feed force of about 59\% was argued to be due to electroplasticity and Joule heating. The torque of EAFSW decreased in the beginning of the welding process. Furthermore, the EAFSW process may be used to weld stronger or thicker materials, which is not possible in the traditional process.

\subsubsection{EA Pressure Welding Process}

$\mathrm{Xu}$ et al. ${ }^{92}$ suggested the electrically-assisted pressure welding process (EAPW) described in Fig. 16. EAPW significantly reduced the pressure welding force and improved the bond strength under a continuous electric current. For example, in the warm pressure weld process, SS316L was not bonded at $75^{\circ} \mathrm{C}$ even with a high welding force. At the same temperature, EAPW can normally weld SS316L at 


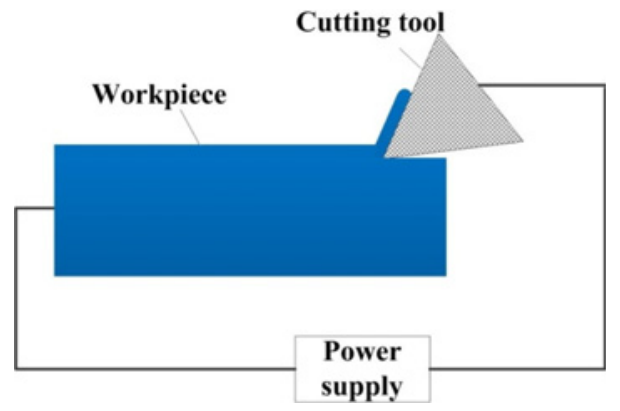

Fig. 17 A simplified schematic of the EA cutting process (modified and redrawn from Ref. 93)

\section{Number of Patents}

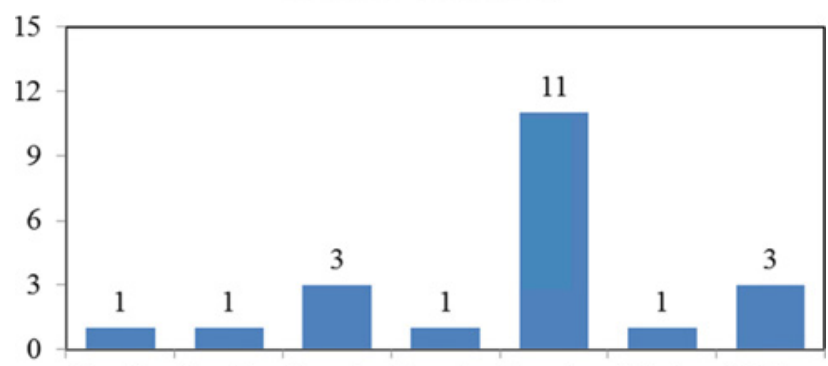

Bending Blanking Drawing Forging Forming Joining Rolling

number of Patents

Fig. 18 Number and distribution of EAM patents

a current density of $20 \mathrm{~A} / \mathrm{mm}^{2}$. Both athermal and thermal effects were argued to contribute to the EAPW process. In addition, the bond area significantly increased from 89.4 to $278.6 \mu \mathrm{m}$.

\subsection{EA Cutting Process}

Baranov et al. ${ }^{93}$ suggested the EA metal cutting process shown in Fig. 17. A relative change in drilling speed was investigated using pieces of copper, steel, duralumin, and cast iron under a pulsed electric current. The friction force and processing time were decreased by $25-$ $30 \%$ and $10-12 \%$, respectively, compared to those of the traditional process. Moreover, the chips, which were produced from a steel piece in the absence of current, were fragile and fine. However, continuous chips also appeared in the EA cutting processes.

\section{Patents}

Recent patents involving EAM are listed in Table 3. Various processes utilize electroplasticity for convenient processes, as shown in Fig. 18. The number of patents involving the forming process represent about $52 \%$ of the total number of patents. In addition to forming processes, rolling processes and drawing processes have also been heavily investigated, each representing around $14 \%$ of the total number of patents. Moreover, in the last five years, the number of patents notably increased by about $52 \%$ based on the data collection.

\section{Conclusions}

The use of electroplasticity in manufacturing processes has many
Table 1 Summarized studies of electroplasticity and mechanical properties

\begin{tabular}{ccc}
\hline $\begin{array}{c}\text { Mechanical } \\
\text { \& structural } \\
\text { properties }\end{array}$ & Summary of the study & Ref. \\
\hline Fatigue & $\begin{array}{c}\text { Increased fatigue resistance } \\
\text { Delayed fatigue crack initiation }\end{array}$ & 22,94 \\
\hline $\begin{array}{c}\text { Residual } \\
\text { stresses }\end{array}$ & Decreased residual stress level & $84,56,95$ \\
\hline $\begin{array}{c}\text { Flow } \\
\text { stress }\end{array}$ & Enhanced plastic deformation & 34,57 \\
\hline $\begin{array}{c}\text { Grain growth } \\
\text { Recrystallization }\end{array}$ & $\begin{array}{c}\text { Accelerated recrystallization } \\
\text { Reduced temperature of recrystallization }\end{array}$ & $\begin{array}{l}27,28, \\
96,97\end{array}$ \\
\hline Fracture & Reduced effective cyclic stress intensity factor \\
and the rate of crack growth & Crack healing \\
\hline $\begin{array}{c}\text { Grains and grain } \\
\text { boundaries }\end{array}$ & $\begin{array}{c}\text { Larger grain size leads to a smaller stress } \\
\text { reduction }\end{array}$ & $\begin{array}{c}57,64, \\
98,99\end{array}$ \\
\hline $\begin{array}{c}\text { Crystal structure } \\
\text { Creep }\end{array}$ & $\begin{array}{c}\text { Stress decrease depends on the crystal structure } \\
\text { (e.g., Bcc more significant than Fcc) }\end{array}$ & 56,100 \\
\hline $\begin{array}{c}\text { Stress } \\
\text { relaxation }\end{array}$ & $\begin{array}{c}\text { Exhibited only at a higher current pulse density } \\
\text { Increases as the time of the applied current increase }\end{array}$ & 100,102 \\
\hline $\begin{array}{c}\text { Brittle } \\
\text { fracture }\end{array}$ & $\begin{array}{c}\text { Controlled crack speed } \\
\text { Current concentrates around the vertex } \\
\text { of a sharp notch }\end{array}$ & 21,103 \\
\hline $\begin{array}{c}\text { Formability } \\
\text { working }\end{array}$ & $\begin{array}{c}\text { Reduction force, temperature Increases } \\
\text { in tensile strength and elongation }\end{array}$ & 21,102 \\
\hline Phase transition & Significantly increased & 35 \\
\hline &
\end{tabular}

Table 2 Review of the advantages of EAM

\begin{tabular}{|c|c|c|}
\hline Processes & Advantages & Ref. \\
\hline Rolling & $\begin{array}{l}\text { Temperature below } \\
\text { the recrystallization temperature } \\
\text { Increased deformability } \\
\text { Increased strength, ductility, } \\
\text { and conservation of plasticity }\end{array}$ & $\begin{array}{l}104- \\
107\end{array}$ \\
\hline Blanking & Decreased blanking load & 85 \\
\hline Bulging & $\begin{array}{l}\text { Increased ratio of height and diameter } \\
\text { Increased formability }\end{array}$ & 108 \\
\hline Drawing & $\begin{array}{l}\text { Drawing stress decreased by } 20-50 \% \\
\text { Significantly improved plasticity } \\
\text { Increased surface quality without } \\
\text { annealing treatment }\end{array}$ & 79 \\
\hline Embossing & $\begin{array}{c}\text { Improved formability } \\
\text { Reduced residual stress } \\
\text { Increased channel depth } \\
\text { Avoid excessive Joule heat and over-heating } \\
\text { of the work piece }\end{array}$ & 84 \\
\hline $\begin{array}{l}\text { Stretch } \\
\text { forming }\end{array}$ & $\begin{array}{l}\text { Create geometrically accurate parts } \\
\text { Smooth surfaces were achievable } \\
\text { Reduced flow stress }\end{array}$ & 86 \\
\hline $\begin{array}{l}\text { Increment } \\
\text { al forming }\end{array}$ & $\begin{array}{c}\text { At low temperature } \\
\text { Decreased forming force }\end{array}$ & 87,88 \\
\hline $\begin{array}{c}\text { Deep } \\
\text { drawing }\end{array}$ & Reduced temperature and force & 83 \\
\hline Forging & $\begin{array}{l}\text { Increased forgeability } \\
\text { Reduced pressure force }\end{array}$ & 39,71 \\
\hline Joining & $\begin{array}{c}\text { Reduced force } \\
\text { Increased bond area } \\
\text { Applicable to industrial manufacturing } \\
\text { on a large scale }\end{array}$ & 91,92 \\
\hline Cutting & Reduced force friction and time cutting & 93 \\
\hline
\end{tabular}


Table 3 A brief review of EAM patents

\begin{tabular}{|c|c|c|c|}
\hline Patent title & Process & $\begin{array}{l}\text { Patent } \\
\text { number }\end{array}$ & Year \\
\hline Electroplastic bending device for light metal section & Bending & CN $102172689 \mathrm{~B}$ & 2011 \\
\hline Electroplastic drawing device of $\mathrm{MgB} 2$ wire and drawing method thereof & Drawing & CN 102489533 A & 2011 \\
\hline Trim apparatus and method for high strength parts & Blanking & KR 101368276 & 2014 \\
\hline Power-Up device for electro-plastic wire drawing & Drawing & CN $201304421 \mathrm{Y}$ & 2007 \\
\hline Electric plastic pulling enhancing process for high-carbon steel wire & Drawing & CN $001613566 \mathrm{~A}$ & 2005 \\
\hline Electro-Plastic open die forging device and method & Forging & CN $102489651 \mathrm{~A}$ & 2012 \\
\hline Strain weakening of metallic materials & Forging & US $20080277034 \mathrm{~A} 1$ & 2008 \\
\hline Electroplastic rotary pressing device & Forming & $\mathrm{CN} 102489575 \mathrm{~A}$ & 2011 \\
\hline Electroplastic incremental forming device and method for plates & Forming & CN $102527830 \mathrm{~A}$ & 2012 \\
\hline Method for plasticizing and forming TiAl-based sheet alloy caused by electricity & Forming & CN $101327506 \mathrm{~A}$ & 2008 \\
\hline Efficient electro-plastic punch forming device & Forming & CN $201552232 \mathrm{U}$ & 2010 \\
\hline Electrical-Assisted double-side incremental forming and processes thereof & Forming & US $20120055217 \mathrm{~A} 1$ & 2011 \\
\hline Single-Point incremental forming of metallic materials using applied DC & Forming & US $8021501 \mathrm{~B} 2$ & 2008 \\
\hline Method and apparatus for electrically assisting the mechanical shaping of a workpiece & Forming & US $5045161 \mathrm{~A}$ & 1990 \\
\hline Techniques for manufacturing a product using EC during plastic deformation materials & Forming & US 7302821 B1 & 2007 \\
\hline Method and apparatus for forming a blank as a portion of the blank receives pulse of DC & Forming & US $7516640 \mathrm{~B} 2$ & 2009 \\
\hline Method for increasing magnesium alloy mechanical property & Forming & $\mathrm{CN} 100532621 \mathrm{C}$ & 2009 \\
\hline Joining apparatus for high-strength parts and joining method therefor & Joining & KR 101368277 & 2014 \\
\hline High-Tensile strength and high-plasticity TiNi nanocrystal material and preparation method thereof & Rolling & CN $102021364 \mathrm{~B}$ & 2011 \\
\hline Electroplastic machining device & Rolling & CN $202438539 \mathrm{U}$ & 2012 \\
\hline Electroplastic rolling method and apparatus for deformable magnesium alloy sheet, band and wire rod & Rolling & CN $100556565 \mathrm{C}$ & 2007 \\
\hline
\end{tabular}

benefits and conveniences such as its ease of manufacture, low manufacturing energy, and good quality of products. Due to the increasing number of recent patents and studies of electroplasticity, many EAM processes are expected to be developed. However, electroplasticity is an on-going study topic and needs to be thoroughly researched. In addition, many processes using electroplasticity have still not been fully developed such as machining, surface treatment, and others bulk deformation processes. Therefore, our work provides an overview of EAM development and insight to manufacturing engineers.

\section{ACKNOWLEDGEMENT}

This work was supported by the Energy Efficiency \& Resources Core Technology Program of the Korea Institute of Energy Technology Evaluation and Planning (KETEP), granted financial resource from the Ministry of Trade, Industry \& Energy, Republic of Korea (No. 20142020103730) and was supported by the Human Resource Training Program for Regional Innovation and Creativity through the Ministry of Education and National Research Foundation of Korea (2013H1B8A20243 82) and by NRF grant (NRF2015R1C1A1A02036321).

\section{REFERENCES}

1. Zhu, Z., Dhokia, V. G., Nassehi, A., and Newman, S. T., "A Review of Hybrid Manufacturing Processes - State of the Art and Future Perspectives," International Journal of Computer Integrated Manufacturing, Vol. 26, No. 7, pp. 596-615, 2013.
2. Cao, X. D., Kim, B. H., and Chu, C. N., "Hybrid Micromachining of Glass Using ECDM and Micro Grinding," Int. J. Precis. Eng. Manuf., Vol. 14, No. 1, pp. 5-10, 2013.

3. Chu, W.-S., Kim, C.-S., Lee, H.-T., Choi, J.-O., Park, J.-I., et al., "Hybrid Manufacturing in Micro/Nano Scale: A Review," Int. J. Precis. Eng. Manuf.-Green Tech., Vol. 1, No. 1, pp. 75-92, 2014.

4. Kim, J.-H., Choi, J.-Y., and Lee, C.-M., "A Study on the Effect of Laser Preheating on Laser Assisted Turn-Mill for Machining Square and Spline Members," Int. J. Precis. Eng. Manuf., Vol. 15, No. 2, pp. 275-282, 2014.

5. Sim, M.-S. and Lee, C.-M., "A Study on the Laser Preheating Effect of Inconel 718 Specimen with Rotated Angle with Respect to 2Axis,” Int. J. Precis. Eng. Manuf., Vol. 15, No. 1, pp. 189-192, 2014.

6. Cho, Y. T. and Na, S. J., "Numerical Analysis of Plasma in $\mathrm{CO}_{2}$ Laser and Arc Hybrid Welding," Int. J. Precis. Eng. Manuf., Vol. 16, No. 4, pp. 787-795, 2015.

7. Lee, S.-J., Kim, J.-D., and Suh, J., "Microstructural Variations and Machining Characteristics of Silicon Nitride Ceramics from Increasing the Temperature in Laser Assisted Machining," Int. J. Precis. Eng. Manuf., Vol. 15, No. 7, pp. 1269-1274, 2014.

8. Ahn, S. H., Chun, D. M., and Kim, C. S., "Nanoscale Hybrid Manufacturing Process by Nano Particle Deposition System (NPDS) and Focused Ion Beam (FIB)," CIRP Annals-Manufacturing Technology, Vol. 60, No. 1, pp. 583-586, 2011.

9. Lin, Y.-C., Chuang, F.-P., Wang, A. C., and Chow, H.-M., "Machining Characteristics of Hybrid EDM with Ultrasonic Vibration and Assisted Magnetic Force," Int. J. Precis. Eng. Manuf., Vol. 15, No. 6, pp. 1143-1149, 2014. 
10. Park, C., Shin, B.-S., Kang, M.-S., Ma, Y.-W., Oh, J.-Y., et al., "Experimental Study on Micro-Porous Patterning Using UV Pulse Laser Hybrid Process with Chemical Foaming Agent," Int. J. Precis. Eng. Manuf., Vol. 16, No. 7, pp. 1385-1390, 2015.

11. Troitskii, O., "Electromechanical Effect in Metals," ZhETF Pisma Redaktsiiu, Vol. 10, p. 18, 1969.

12. Okazaki, K., Kagawa, M., and Conrad, H., "A Study of the Electroplastic Effect in Metals," Scripta Metallurgica, Vol. 12, No. 11, pp. 1063-1068, 1978.

13. Sprecher, A. F., Conrad, H., and Mannan, S. L., "The Electroplastic Effect in Metals," North Carolina State University, 1984.

14. Ross, C. D., Irvin, D. B., and Roth, J. T., "Manufacturing Aspects Relating to the Effects of Direct Current on the Tensile Properties of Metals," Journal of Engineering Materials and Technology, Vol. 129, No. 2, pp. 342-347, 2007.

15. Perkins, T. A., Kronenberger, T. J., and Roth, J. T., "Metallic Forging Using Electrical Flow as an Alternative to Warm/Hot Working," Journal of Manufacturing Science and Engineering, Vol. 129, No. 1, pp. 84-94, 2007.

16. Roth, J., Loker, I., Mauck, D., Warner, M., Golovashchenko, S., et al., "Enhanced Formability of 5754 Aluminum Sheet Metal Using Electric Pulsing," Transactions of the North American Manufacturing Research Institute of SME, Vol. 36, pp. 405-412, 2008.

17. Kim, M.-J., Lee, K., Oh, K. H., Choi, I.-S., Yu, H.-H., et al., "Electric Current-Induced Annealing during Uniaxial Tension of Aluminum Alloy," Scripta Materialia, Vol. 75, pp. 58-61, 2014.

18. Roh, J.-H., Seo, J.-J., Hong, S.-T., Kim, M.-J., Han, H. N., et al., "The Mechanical Behavior of 5052-H32 Aluminum Alloys under a Pulsed Electric Current," International Journal of Plasticity, Vol. 58, pp. 84-99, 2014.

19. Salandro, W. A., Jones, J. J., McNeal, T. A., Roth, J. T., Hong, S.-T., et al., "Formability of Al 5xxx Sheet Metals Using Pulsed Current for Various Heat Treatments," Journal of Manufacturing Science and Engineering, Vol. 132, No. 5, Paper No. 051016, 2010.

20. Troitskii, O., "Effect of the Electron State of a Metal on Its Mechanical Properties and the Phenomenon of Electroplasticity," Strength of Materials, Vol. 9, No. 1, pp. 35-45, 1977.

21. Sprecher, A., Mannan, S., and Conrad, H., "Overview No. 49: On the Mechanisms for the Electroplastic Effect in Metals," Acta Metallurgica, Vol. 34, No. 7, pp. 1145-1162, 1986.

22. Conrad, H., White, J., Cao, W., Lu, X., and Sprecher, A., "Effect of Electric Current Pulses on Fatigue Characteristics of Polycrystalline Copper," Materials Science and Engineering: A, Vol. 145, No. 1, pp. 1-12, 1991.

23. Ogwu, A. and Davies, T., "Practical Applications of the Electron Theory to Improve Physical and Mechanical Properties of Engineering Materials," Journal of Materials Science, Vol. 29, No. 6, pp. 1623-1628, 1994.

24. Okazaki, K., Kagawa, M., and Conrad, H., "An Evaluation of the Contributions of Skin, Pinch and Heating Effects to the
Electroplastic Effect in Titatnium," Materials Science and Engineering, Vol. 45, No. 2, pp. 109-116, 1980.

25. Conrad, H., Sprecher Jr, A., Cao, W., and Lu, X., "Electroplasticity: The Effect of Electricity on the Mechanical Properties of Metals," JOM, Vol. 42, No. 9, pp. 28-33, 1990.

26. Zhen, S., Zu, H., and Yong, X., "Effect of Electric Current on the Recrystallization Behaviour of Cold Worked Alpha-Ti," Scripta Metallurgica, Vol. 22, No. 2, pp. 187-190, 1988.

27. Jiang, Y., Tang, G., Shek, C., and Liu, W., "Microstructure and Texture Evolution of the Cold-Rolled AZ91 Magnesium Alloy Strip under Electropulsing Treatment," Journal of Alloys and Compounds, Vol. 509, No. 11, pp. 4308-4313, 2011.

28. Jiang, Y., Tang, G., Shek, C., Xie, J., Xu, Z., et al., "Mechanism of Electropulsing Induced Recrystallization in a Cold-Rolled Mg9Al-1Zn Alloy," Journal of Alloys and Compounds, Vol. 536, pp. 94-105, 2012.

29. Gilman, J. J., "Electro-Plastic Effect in Semiconductors," Materials Science and Engineering: A, Vol. 287, No. 2, pp. 272-275, 2000.

30. Heigel, J. C., Andrawes, J. S., Roth, J. T., Hoque, M. E., and Ford, R. M., "Viability of Electrically Treating 6061 T6511 Aluminum for Use in Manufacturing Processes," Transactions of the North American Manufacturing Research Institute of SME, Vol. 33, pp. 145-152, 2005.

31. Zhao, Y., Ma, B., Guo, H., Ma, J., Yang, Q., et al., "Electropulsing Strengthened 2GPa Boron Steel with Good Ductility," Materials \& Design, Vol. 43, pp. 195-199, 2013.

32. To, S., Zhu, Y., Lee, W., Liu, X., and Jiang, Y., "Effects of Current Density on Elongation of an Electropulsing Treated Zn-Al Based Alloy," Materials Transactions, Vol. 50, No. 12, pp. 2772-2777, 2009.

33. Huang, X., "Residual Stress Reduction by Combined Treatment of Pulsed Magnetic Field and Pulsed Current," Materials Science and Engineering: A, Vol. 528, No. 19, pp. 6287-6292, 2011.

34. Guan, L., Tang, G., and Chu, P. K., "Recent Advances and Challenges in Electroplastic Manufacturing Processing of Metals," Journal of Materials Research, Vol. 25, No. 7, pp. 1215-1224, 2010.

35. Zhang, D., To, S., Zhu, Y., Wang, H., and Tang, G, "Dynamic Electropulsing Induced Phase Transformations and Their Effects on Single Point Diamond Turning of AZ91 Alloy," Journal of Surface Engineered Materials and Advanced Technology, Vol. 2, No. 1, pp. 16-21, 2012.

36. Salandro, W., Khalifa, A., and Roth, J., "Tensile Formability Enhancement of Magnesium AZ31B-O Alloy Using Electrical Pulsing," Transactions of the North American Manufacturing Research Institute of SME, Vol. 37, pp. 387-394, 2009.

37. Salandro, W. A., Bunget, C., and Mears, L., "Thermo-Mechanical Investigations of the Electroplastic Effect," Proc. of ASME International Manufacturing Science and Engineering Conference, pp. 573-582, 2011. 
38. Dzialo, C., Siopis, M., Kinsey, B., and Weinmann, K., "Effect of Current Density and Zinc Content during Electrical-Assisted Forming of Copper Alloys," CIRP Annals-Manufacturing Technology, Vol. 59, No. 1, pp. 299-302, 2010.

39. Ross, C. D., Kronenberger, T. J., and Roth, J. T., "Effect of DC on the formability of Ti-6Al-4V," Journal of Engineering Materials and Technology, Vol. 131, No. 3, Paper No. 031004, 2009.

40. Salandro, W. A., Bunget, C., and Mears, L., "Modeling and Quantification of the Electroplastic Effect When Bending Stainless Steel Sheet Metal," Proc. of ASME International Manufacturing Science and Engineering Conference, pp. 581590,2010

41. Salandro, W. A., Bunget, C. J., and Mears, L., "A Thermal-Based Approach for Determining Electroplastic Characteristics," Proc. of the Institution of Mechanical Engineers, Part B: Journal of Engineering Manufacture, Paper No. 0954405411424696, 2012.

42. Conrad, H., "Electroplasticity in Metals and Ceramics," Materials Science and Engineering: A, Vol. 287, No. 2, pp. 276-287, 2000.

43. Conrad, H., "Thermally Activated Plastic Flow of Metals and Ceramics with an Electric Field or Current," Materials Science and Engineering: A, Vol. 322, No. 1, pp. 100-107, 2002.

44. Kravchenko, V. Y., "Effect of Directed Electron Beam on Moving Dislocations," Soviet Physics JETP, Vol. 24, No. 6, pp. 1135-1142, 1967.

45. Cao, W., Sprecher, A., and Conrad, H., "Measurement of the Electroplastic Effect in Nb," Journal of Physics E: Scientific Instruments, Vol. 22, No. 12, Paper No. 1026, 1989.

46. Fiks, V., "Interaction of Conduction Electrons with Single Dislocations in Metals," Soviet Physics JETP, Vol. 53, pp. 12091211, 1981.

47. Li, D. L. and Yu, E. L., "An Approach Based on the Classical FreeElectron Theory to Study Electroplastic Effect," Advanced Materials Research, pp. 71-74, 2011.

48. Li, D. L., Yu, E. L., and Liu, Z. T., "Mechanism Research and Progress of Metal's Pure Electroplastic Effect," Applied Mechanics and Materials, Vol. 184-185, pp. 1060-1063, 2012.

49. Goldman, P., Motowidlo, L., and Galligan, J., "The Absence of an Electroplastic Effect in Lead at 4.2 K," Scripta Metallurgica, Vol. 15, No. 4, pp. 353-356, 1981.

50. Magargee, J., Morestin, F., and Cao, J., "Characterization of Flow Stress for Commercially Pure Titanium Subjected to Electrically Assisted Deformation," Journal of Engineering Materials and Technology, Vol. 135, No. 4, Paper No. 041003, 2013.

51. Magargee, J., Fan, R., and Cao, J., "Analysis and Observations of Current Density Sensitivity and Thermally Activated Mechanical Behavior in Electrically-Assisted Deformation," Journal of Manufacturing Science and Engineering, Vol. 135, No. 6, Paper No. 061022, 2013.
52. Kir'yanchev, N., Troitskii, O., and Klevtsur, S., "Electroplastic Deformation of Metals (Review)," Strength of Materials, Vol. 15, No. 5, pp. 709-715, 1983.

53. Xu, Q., Guan, L., Jiang, Y., Tang, G., and Wang, S., "Improved Plasticity of Mg-Al-Zn Alloy by Electropulsing Tension," Materials Letters, Vol. 64, No. 9, pp. 1085-1087, 2010.

54. Ulacia, I., Salisbury, C., Hurtado, I., and Worswick, M., "Tensile Characterization and Constitutive Modeling of AZ31B Magnesium Alloy Sheet over Wide Range of Strain Rates and Temperatures," Journal of Materials Processing Technology, Vol. 211, No. 5, pp. 830-839, 2011.

55. Song, J. H., Lee, J., Kim, Y. B., Choi, S., Lee, G. A., et al., "Influences of Pulsed Electric Current on Mechanical Properties of DP and Trip Steel Sheets," Proc. of the International Conference on Advance Research in Mechanical, pp. 84-88, 2013.

56. Liu, X., Lan, S., and Ni, J., "Experimental Study of Electro-Plastic Effect on Advanced High Strength Steels," Materials Science and Engineering: A, Vol. 582, pp. 211-218, 2013.

57. Fan, R., Magargee, J., Hu, P., and Cao, J., "Influence of Grain Size and Grain Boundaries on the Thermal and Mechanical Behavior of 70/30 Brass under Electrically-Assisted Deformation," Materials Science and Engineering: A, Vol. 574, pp. 218-225, 2013.

58. Mai, J., Peng, L., Lin, Z., and Lai, X., "Experimental Study of Electrical Resistivity and Flow Stress of Stainless Steel 316L in Electroplastic Deformation," Materials Science and Engineering: A, Vol. 528, No. 10, pp. 3539-3544, 2011.

59. Kinsey, B., Cullen, G., Jordan, A., and Mates, S., "Investigation of Electroplastic Effect at High Deformation Rates for 304SS and Ti6Al-4V," CIRP Annals-Manufacturing Technology, Vol. 62, No. 1, pp. 279-282, 2013.

60. Stolyarov, V., "Influence of Structural Scale and Pulsed Current on the Mechanical Behavior of TiNi alloy with Shape Memory," Steel in Translation, Vol. 39, No. 10, pp. 858-862, 2009.

61. Stolyarov, V. V., "Electroplastic Effect in Nanostructured Titanium Alloys," Reviews on Advanced Materials Science, Vol. 31, pp. 163 $166,2012$.

62. Zhu, Y., To, S., Liu, X., and Hu, G., "Effect of Static Electropulsing on Microstructure and Elongation of a Zn-Al Alloy (ZA22)," Metallurgical and Materials Transactions A, Vol. 42, No. 7, pp. 1933-1940, 2011.

63. Mears, M. L., Mehta, P., Kuttolamadom, M., Montes, C., Jones, J., et al., "Manufacturing Process Modeling and Application to Intelligent Control," Journal of the South Carolina Academy of Science, Vol. 10, No. 1, 2012.

64. Siopis, M. S. and Kinsey, B. L., "Experimental Investigation of Grain and Specimen Size Effects during Electrical-Assisted Forming," Journal of Manufacturing Science and Engineering, Vol. 132, No. 2, Paper No. 021004, 2010. 
65. Hong, S.-T. and Weil, K. S., "Niobium-Clad 304L Stainless Steel PEMFC Bipolar Plate Material: Tensile and Bend Properties," Journal of Power Sources, Vol. 168, No. 2, pp. 408-417, 2007.

66. Kim, D., Kim, J., Lee, M., Lee, Y., and Kang, S., "Experimental Investigation into Effect of Annealing Treatment on Springback of Magnesium Alloy Sheets," Materials Research Innovations, Vol. 15, No. s1, pp. s183-s186, 2011.

67. Kim, M.-S., Vinh, N. T., Yu, H.-H., Hong, S.-T., Lee, H.-W., et al., "Effect of Electric Current Density on the Mechanical Property of Advanced High Strength Steels under Quasi-Static Tensile Loads,” Int. J. Precis. Eng. Manuf., Vol. 15, No. 6, pp. 1207-1213, 2014.

68. Green, C. R., McNeal, T. A., and Roth, J. T., "Springback Elimination for Al-6111 Alloys Using Electrically-Assisted Manufacturing (EAM)," North American Manufacturing Research Institution of SME, Vol. 37, pp. 403-410, 2009.

69. Parkansky, N., Molotskii, M., Alterkop, B., Goldsmith, S., Boxman, R., et al., "Low Current Electroplastic Effect in Ferromagnetic Materials," Journal of Applied Physics, Vol. 89, No. 10, pp. 5597-5600, 2001.

70. Jones, J. J., Mears, L., and Roth, J. T., "Electrically-Assisted Forming of Magnesium AZ31: Effect of Current Magnitude and Deformation Rate on Forgeability," Journal of Manufacturing Science and Engineering, Vol. 134, No. 3, Paper No. 034504, 2012.

71. Bunget, C., Salandro, W., Mears, L., and Roth, J. T., "Energy-Based Modeling of an Electrically-Assisted Forging Process," North American Manufacturing Research Institution of SME, Vol. 38, pp. 647-654, 2010.

72. Xu, Z., Tang, G., Tian, S., Ding, F., and Tian, H., "Research of Electroplastic Rolling of AZ31 Mg Alloy Strip,” Journal of Materials Processing Technology, Vol. 182, No. 1, pp. 128-133, 2007.

73. Lu, Y., Qu, T., Zeng, P., Lei, L., Fang, G., et al., "The Influence of Electroplastic Rolling on the Mechanical Deformation and Phase Evolution of Bi-2223/Ag Tapes," Journal of Materials Science, Vol. 45, No. 13, pp. 3514-3519, 2010.

74. Zhu, R., Tang, G., Shi, S., and Fu, M., "Effect of Electroplastic Rolling on Deformability and Oxidation of Nitinb Shape Memory Alloy," Journal of Materials Processing Technology, Vol. 213, No. 1, pp. 30-35, 2013.

75. Zhu, R., Tang, G., Shi, S., and Fu, M., "Effect of Electroplastic Rolling on the Ductility and Superelasticity of TiNi Shape Memory Alloy,” Materials \& Design, Vol. 44, pp. 606-611, 2013.

76. Ng, M.-K., Fan, Z., Gao, R. X., Smith, E. F., and Cao, J., "Characterization of Electrically-Assisted Micro-Rolling for Surface Texturing Using Embedded Sensor," CIRP Annals-Manufacturing Technology, Vol. 63, No. 1, pp. 269-272, 2014.

77. Tang, G., Zhang, J., Zheng, M., Zhang, J., Fang, W., et al., "Experimental Study of Electroplastic Effect on Stainless Steel Wire 304L," Materials Science and Engineering: A, Vol. 281, No. 1, pp. 263-267, 2000.
78. Yao, K.-F., Wang, J., Zheng, M., Yu, P., and Zhang, H., “A Research on Electroplastic Effects in Wire-Drawing Process of an Austenitic Stainless Steel," Scripta Materialia, Vol. 45, No. 5, pp. 533-539, 2001.

79. Tang, G., Zhang, J., Yan, Y., Zhou, H., and Fang, W., "The Engineering Application of the Electroplastic Effect in the ColdDrawing of Stainless Steel Wire," Journal of Materials Processing Technology, Vol. 137, No. 1, pp. 96-99, 2003.

80. Zimniak, Z. and Radkiewicz, G., "The Electroplastic Effect in the Cold-Drawing of Copper Wires for the Automotive Industry," Archives of Civil and Mechanical Engineering, Vol. 8, No. 2, pp. 173-179, 2008.

81. Stashenko, V., Troitskii, O., and Novikova, N., "Electroplastic Drawing of a Cast-Iron Wire," Journal of Machinery Manufacture and Reliability, Vol. 38, No. 2, pp. 182-184, 2009.

82. Stashenko, V., Troitskii, O., and Novikova, N., "Electroplastic Drawing Medium-Carbon Steel," Journal of Machinery Manufacture and Reliability, Vol. 38, No. 4, pp. 369-372, 2009.

83. Wang, S., "Effect of Electric Pulses on Drawability and Corrosion Property of AZ31 Magnesium Alloy," M.Sc. Thesis, Materials Science and Engineering, Tsinghua University, 2009.

84. Mai, J., Peng, L., Lai, X., and Lin, Z., "Electrical-Assisted Embossing Process for Fabrication of Micro-Channels on 3161 Stainless Steel Plate," Journal of Materials Processing Technology, Vol. 213, No. 2, pp. 314-321, 2013.

85. Kim, W., Yeom, K.-H., Thien, N. T., Hong, S.-T., Min, B.-K., et al., "Electrically Assisted Blanking Using the Electroplasticity of UltraHigh Strength Metal Alloys," CIRP Annals-Manufacturing Technology, Vol. 63, No. 1, pp. 273-276, 2014.

86. Jones, J. J. and Mears, L., “A Process Comparison of Simple Stretch Forming Using both Conventional and Electrically-Assisted Forming Techniques," Proc. of ASME International Manufacturing Science and Engineering Conference, pp. 623-631, 2010.

87. Cao, J., Xia, Z. C., Gutowski, T. G., and Roth, J., "A Hybrid Forming System: Electrical-Assisted Double Side Incremental Forming (EADSIF) Process for Enhanced Formability and Geometrical Flexibility," Northwestern University, Document ID: DE-EE0003460, 2012.

88. Asghar, J. and Reddy, N., "Importance of Tool Configuration in Incremental Sheet Metal Forming of Difficult to Form Materials Using Electro-Plasticity," Proc. of the World Congress on Engineering, Vol. 3, 2013.

89. Ferrando, W. A., "The Concept of Electrically Assisted Friction Stir Welding (EAFSW) and Application to the Processing of Various Metals," DTIC Document, 2008.

90. Pitschman, M., Dolecki, J. W., Johns, G. W., Zhou, J., and Roth, J. T., "Application of Electric Current in Friction Stir Welding," Proc. of ASME International Manufacturing Science and Engineering Conference, pp. 185-189, 2010. 
91. Potluri, H., Jones, J. J., and Mears, L., “Comparison of ElectricallyAssisted and Conventional Friction Stir Welding Processes by Feed Force and Torque," Proc. of ASME International Manufacturing Science and Engineering Conference Collocated with the $41^{\text {st }}$ North American Manufacturing Research Conference, Paper No. MSEC2013-1192, 2013.

92. Xu, Z. T., Peng, L. F., Yi, P. Y., and Lai, X. M., "Study on a Novel Electrical-Assisted Pressure Welding Process of Thin Metallic Foils," Applied Mechanics and Materials, Vol. 271-272, pp. 147-151, 2013.

93. Baranov, S. A., Staschenko, V. I., Sukhov, A. V., Troitskiy, O. A., and Tyapkin, A. V., "Electroplastic Metal Cutting," Russian Electrical Engineering, Vol. 82, No. 9, pp. 477-479, 2011.

94. Tang, Y., Hosoi, A., Iwase, Y., and Ju, Y., "Effect of High-Density Electric Current on the Microstructure and Fatigue Crack Initiation of Stainless Steel," Materials Transactions, Vol. 54, No. 11, pp. 2085-2092, 2013.

95. Stepanov, G., Babutskii, A., Chizhik, A., and Gromov, V., "Pulse Electric Current Effect on Mechanical Properties of Titanium Aluminide Produced by the Self-Propagating High-Temperature Synthesis Technique," Strength of Materials, Vol. 44, No. 6, pp. 636-644, 2012.

96. Yao, K., Yu, P., and Wang, J., "Effects of High-Density Current Pulses on Workhardening Behaviors of Austenite Stainless Steelin Wire-Drawing Deformation," Acta Metallurgica Sinica (English Letters), Vol. 14, No. 5, pp. 341-346, 2009.

97. Hu, G., Shek, C., Zhu, Y., Tang, G., and Qing, X., "Effect of Electropulsing on recrystallization of Fe-3\% Si Alloy Strip," Materials Transactions, Vol. 51, No. 8, pp. 1390-1394, 2010.

98. Conrad, H., "Effects of Electric Current on Solid State Phase Transformations in Metals," Materials Science and Engineering: A, Vol. 287, No. 2, pp. 227-237, 2000

99. Guan, L., Tang, G., Jiang, Y., and Chu, P. K., "Texture Evolution in ColdRolled AZ31 Magnesium Alloy during Electropulsing Treatment," Journal of Alloys and Compounds, Vol. 487, No. 1, pp. 309-313, 2009.

100.Stepanov, G. and Babutskii, A., "Effect of Electric Current on Stress Relaxation in Metal," Strength of Materials, Vol. 28, No. 2, pp. 125-128, 1996.

101.Stashenko, V., Troitskii, O., and Spitsyn, V., "Action of Current Pulses on Zinc Single Crystals during Creep," Physica Status Solidi (a), Vol. 79, No. 2, pp. 549-557, 1983.

102.Stepanov, G., Babutskii, A., and Mameev, I., "High-Density Pulse Current-Induced Unsteady Stress-Strain State in a Long Rod," Strength of Materials, Vol. 36, No. 4, pp. 377-381, 2004.

103.Golovin, Y. I., Finkel', V., and Sletkov, A., "Effects of Current Pulses on Crack Propagation Kinetics in Silicon Iron," Strength of Materials, Vol. 9, No. 2, pp. 204-210, 1977.

104.Mal'tsev, I., "Electroplastic Rolling of Metals with a High-Density Current," Russian Journal of Non-Ferrous Metals, Vol. 49, No. 3, pp. 175-180, 2008.
105.Stolyarov, V., "Deformability and Nanostructuring of TiNi ShapeMemory Alloys during Electroplastic Rolling," Materials Science and Engineering: A, Vol. 503, No. 1, pp. 18-20, 2009.

106.Stolyarov, V., Pashinskaya, E., and Beigel'zimer, Y. E., "Effect of Combined Deformation on the Structure and Properties of Copper and Titanium Alloys," Russian Metallurgy (Metally), Vol. 2010, No. 10, pp. 904-909, 2010.

107.Yuryev, V., Baranov, Y. V., Stolyarov, V., Shulga, V., and Kostina, I., "Effect of Electroplastic Processing on the Structure of AluminumLithium Alloy 1463," Bulletin of the Russian Academy of Sciences: Physics, Vol. 72, pp. 1248-1250, 2008.

108.Li, C., Zhang, K., Jiang, S., and Zhao, Z., "Pulse Current Auxiliary Bulging and Deformation Mechanism of AZ31 Magnesium Alloy," Materials and Design, Vol. 34, pp. 170-178, 2012. 